Frederick A. Burrows MD FRCPC, J.B. Norton MD, James Fewel PH D

\title{
Cardiovascular and respiratory effects of ketamine in the neonatal lamb
}

To determine the cardiovascular and respiratory effects of intravenous ketamine in the neonatal lamb we studied six unpremedicated chronic neonatal lamb preparations. Each lamb was anaesthetized with ketamine $1 \mathrm{mg} \cdot \mathrm{kg}^{-1}$, allowed to recover and then anaesthetized with ketamine $2 \mathrm{mg} \cdot \mathrm{kg}^{-1}$. Mean arterial pressure, mean pulmonary artery pressure, mean left atrial pressure, pulmonary blood flow, heart rate, respiratory rate and arterial blood gases were measured before and at one, two, four, six, eight and ten minutes after the administration of each dose of ketamine. Pulmonary vascular resistance, systemic vascular resistance and the ratio of pulmonary to systemic vascular resistance were also determined. After the administration of either dose of ketamine, only respiratory rate changed significantly $(p \leq 0.05)$, reaching a maximum after two minutes. This change was not associated with any arterial blood gas abnormalities. We conclude that in the presence of adequate ventilation, ketamine produces no significant cardiovascular effects in neonatal lambs.

\section{Key words}

ANAESTHETICS, INTRAVENOUS: ketamine: ANAESTHESIA: paediatric, neonatal.

From the Departments of Anesthesia and Pediatrics, University of Arkansas for Medical Sciences and the Arkansas Children's Hospital, Little Rock, Arkansas, U.S.A. and the Department of Anaesthesia, The Hospital for Sick Children and University of Toronto, Toronto, Ontario.

Address correspondence to: Dr. F.A. Burrows, Department of Anaesthesia, The Hospital for Sick Children, 555 University Avenue, Toronto, Ontario, M5G 1X8.
Ketamine hydrochloride is an agent frequently recommended for the induction of anaesthesia in children with congenital heart defects ${ }^{1-4}$ and for sedation during cardiac catheterization. ${ }^{5,6}$ It is also recommended for sedation of unco-operative neonates, infants and children for diagnostic procedures such as computerized tomography. ${ }^{7,8}$ Although ketamine provides a stable level of anaesthesia, excellent analgesia, maintenance of respiratory reflexes and drive and maintenance of cardiovascular function,, 10 it has been reported to produce hypoxaemia and elevations in pulmonary vascular resistance (Rp). ${ }^{11-13}$

The cardiovascular effects of intravenous ketamine have been studied in both animals and humans, ${ }^{11-14}$ but its effects in infants are not clear. Ketamine is reported to have no significant influence on the circulation in children either before or after surgical repair of their congenital heart lesions. ${ }^{15-17}$ Hickey et al. ${ }^{17}$ suggested that the effects of ketamine in children apply to infants with similar defects. However, the myocardium and pulmonary circulation differ markedly between infants and children.

Futhermore, there is no study on the effect of the administration of ketamine on the cardiovascular system of the intact normal neonate or infant. Extrapolation of work done in children with congenital heart defects may not be relevant as their results may reflect the influence of the disease process on the myocardium and the pulmonary circulation. The purpose of our study, therefore, was to examine the effect of ketamine on the cardiovascular variables in the neonatal lamb model with a normal cardiovascular system.

\section{Methods}

We studied six chronically instrumented newborn lambs weighing $<6 \mathrm{~kg}$ and less than eight days old. Each animal had undergone a lateral thoracotomy 
one day after birth (Day 1). Left atrial (LA) and pulmonary arterial (PA) \#5 French polyethylene catheters were inserted. The aortic catheter was inserted through the femoral artery and positioned in the abdominal aorta. Blood loss was less than $5 \mathrm{ml}$. Cardiac output (Qp) was monitored with a Gould Statham Flow meter SP2202 with Statham flow transducers from the $S p 7515$ series. The transducers were 8,9 or $10 \mathrm{~mm}$ in diameter depending on the size of the PA. Where present, patent ductus arteriosis was ligated. The lambs were allowed to recover for three days.

The electroencephalogram (EEG) was monitored by standard bipolar parietal leads. Heart rate (HR) was calculated from the peak-to-peak interval of the arterial pressure trace. The data were recorded simultaneously on an Electronics for Medicine ${ }^{\$}$ 12-channel recorder. Arterial blood gas analysis ( $\mathrm{pH}, \mathrm{PCO}_{2}, \mathrm{PO}_{2}$ and base excess) was performed (Corning $165^{(1)}$ ) Volume equivalent to blood withdrawn for analysis (approximately $10 \mathrm{ml}$ ) was transfused into the lamb immediately after sampling.

The study was performed on Day 5. Recovery from surgery was assessed solely by observation of the animal. The animal was considered suitable for further study if there were no signs of infection or obvious restriction of movement due to the site of surgery.

The lambs were suspended in a sling in the upright position and were nursed from a bottle. The

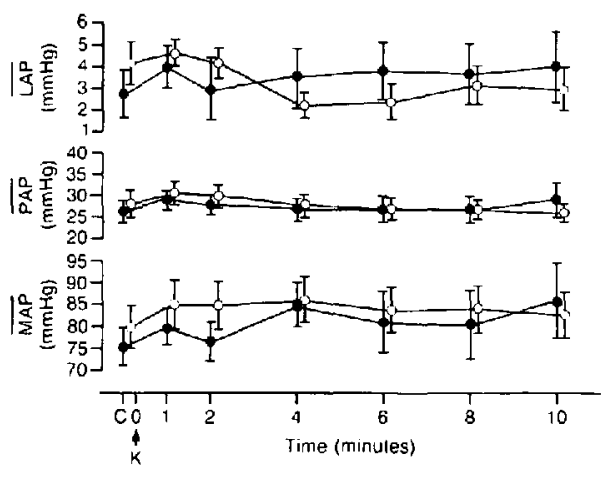

FIGURE $1 \overline{\mathrm{MAP}}, \overline{\mathrm{PAP}}$ and $\overline{\mathrm{LAP}}$ control values (C) and after administration of ketamine (K) $1 \mathrm{mg} \cdot \mathrm{kg}^{-1}(\mathrm{O}-\mathrm{O})$ and $2 \mathrm{mg} \cdot \mathrm{kg}^{-1}(\mathrm{O}-\mathrm{O})$. The bars represent the standard ertor of the mean (SEM) transducers were mounted on a rack next to the animal at mid-thoracic level. To provide a quiet environment for the lambs all equipment was positioned outside the room and the animal was visualized with a remote camera.

Each lamb was studied twice: first, $1 \mathrm{mg} \cdot \mathrm{kg}^{-1}$ ketamine was administered and then, after return of the EEG and cardiovascular variables to control levels (at least one hour), $2 \mathrm{mg} \cdot \mathrm{kg}^{-1} \mathrm{ketamine}$ was administered. The ketamine was administered into the LA line over 30 seconds. During each study, control measurements were made immediately before ketamine administration.

Systemic vascular resistance (Rs) was calculated from the formula:

$$
\begin{aligned}
\mathrm{Rs}\left(\mathrm{mmHg} \cdot \mathrm{ml}^{-1} \cdot \mathrm{kg}^{-1}\right) & \\
& =\frac{\text { mean arterial pressure }(\overline{\mathrm{MAP}})}{\text { cardiac output }(\mathrm{Qp})}
\end{aligned}
$$

and pulmonary vascular resistance from the formula:

$$
\begin{array}{r}
\mathrm{Rp}\left(\mathrm{mmHg} \cdot \mathrm{ml}^{-1} \cdot \mathrm{min}^{-1} \cdot \mathrm{kg}^{-1}\right) \\
\text { mean pulmonary } \\
=\frac{\begin{array}{l}
\text { artery pressure }(\overline{\mathrm{PAP}}) \\
\text { pressure }(\overline{\mathrm{LAP}})
\end{array}}{\mathrm{Qp}}
\end{array}
$$

Statistical significance ( $p \leq 0.05$ ) was determined using the Bonferonni $t$ test, analysis of variance and the Student-Newman-Keuls multiple range test.

\section{Results}

The control values for $\overline{\mathrm{MAP}}, \overline{\mathrm{PAP}}, \overline{\mathrm{LAP}}, \mathrm{HR}, \mathrm{RR}$, $\mathrm{Qp}, \mathrm{Rp}, \mathrm{Rs}$ and $\mathrm{Rp} \cdot \mathrm{Rs}^{-1}$ did not differ significantly between the two doses of ketamine (Figures 1-3). Only RR changed significantly during the study periods. Control RR was $48.17 \pm 4.98$ breaths per minute (BPM) before ketamine $1 \mathrm{mg} \cdot \mathrm{kg}^{-1}$ and $52.2 \pm 3.47 \mathrm{BPM}$ before ketamine $2 \mathrm{mg} \cdot \mathrm{kg}^{-1}$. RR increased significantly reaching a maximum two minutes after administration of either dose of ketamine $\left(80 \pm 7.96 \mathrm{BPM}\right.$ for ketamine $1 \mathrm{mg} \cdot \mathrm{kg}^{-1}$ and $95.4 \pm 8.17 \mathrm{BPM}$ after ketamine $2 \mathrm{mg} \cdot \mathrm{kg}^{-1}$ ). $R R$ no longer differed significantly from control six minutes after the administration of ketamine $1 \mathrm{mg} \cdot \mathrm{kg}^{-1}$ but still significantly increased $(68.2 \pm$ 11.61 BPM) above control ten minutes after the administration of ketamine $2 \mathrm{mg} \cdot \mathrm{kg}^{-1}$. Arterial $\mathrm{pH}$, 

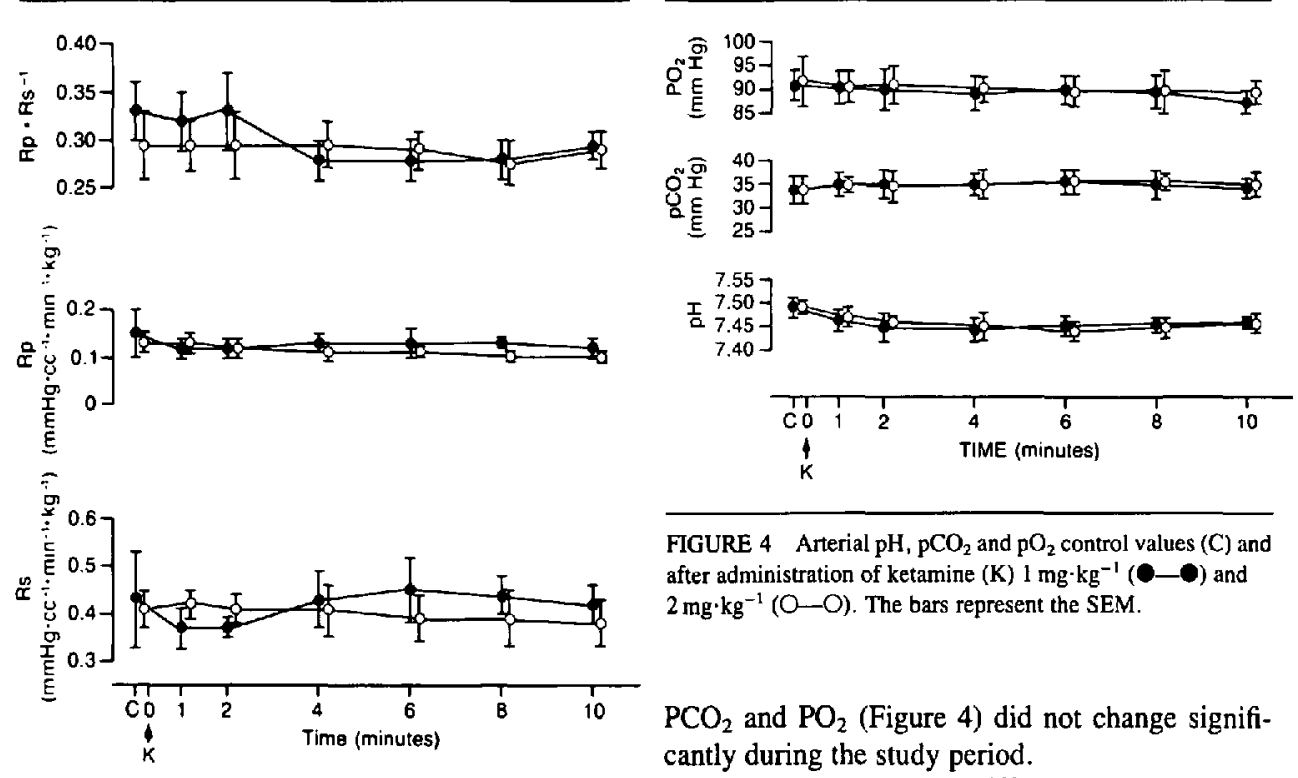

FIGURE 4 Arterial $\mathrm{pH}_{1} \mathrm{pCO}_{2}$ and $\mathrm{pO}_{2}$ control values $(\mathrm{C})$ and after administration of ketamine (K) $1 \mathrm{mg} \cdot \mathrm{kg}^{-1}(\mathbf{Q}-)$ and $2 \mathrm{mg} \cdot \mathrm{kg}^{-1}(\mathrm{O}-\mathrm{O})$. The bars represent the SEM.

FIGURE 2 Rs, Rp and the Rp-to-Rs ratio control values (C) and after administration of ketamine (K) $1 \mathrm{mg} \cdot \mathrm{kg}^{-1}($ and $2 \mathrm{mg} \cdot \mathrm{kg}^{-1}(\mathrm{O}-\mathrm{O})$. The bars represent SEM.

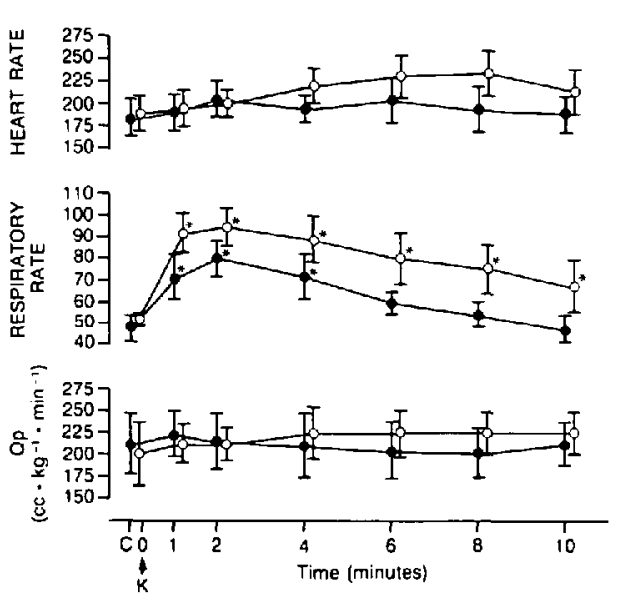

$\mathrm{PCO}_{2}$ and $\mathrm{PO}_{2}$ (Figure 4) did not change significantly during the study period.

There was no statistical difference in any variable between the two doses of ketamine.

\section{Discussion}

Ketamine ( $1 \mathrm{mg} \cdot \mathrm{kg}^{-1}$ or $\left.2 \mathrm{mg} \cdot \mathrm{kg}^{-1}\right)$ produced no significant cardiovascular changes when administered to neonatal lambs with normal, intact cardiovascular anatomy. However, it did increase the respiratory rate without significant changes in the arterial blood gases.

The effect of ketamine on the cardiovascular system varies with age. In adults, ketamine stimulates the cardiovascular system. ${ }^{18-22}$ In the absence of autonomic control, however, ketamine directly depresses the myocardium. ${ }^{23,24}$ The effect of ketamine on the cardiovascular system in children is not clear. In children undergoing cardiac catheterization, previous studies reported increases in blood pressure ${ }^{15}$ and heart rate ${ }^{16}$ while others reported no change in blood pressure, heart rate or cardiac index. ${ }^{17}$ Our data suggest the lack of significant effect of ketamine on the cardiovascular system in neonatal lambs.

Ketamine increases the pulmonary artery pressure

FIGURE 3 Qp, RR and HR control values (C) and after administration of ketamine (K) $1 \mathrm{mg} \cdot \mathrm{kg}^{-1}(\mathrm{O}-)$ or $2 \mathrm{mg} \cdot \mathrm{kg}^{-1}(\mathrm{O}-\mathrm{O})$. The bars represent the SEM. and pulmonary vascular resistance in adults $12,14,25$ and in children. ${ }^{16}$ In infants and neonates, however, our results and other recent findings suggest ketamine 1 or $2 \mathrm{mg} \cdot \mathrm{kg}^{-1}$ has no significant effect on either 
the pulmonary artery pressure or the pulmonary vascular resistance $\left(\mathrm{Rp} \cdot \mathrm{Rs}^{-1}\right) .{ }^{17}$ This age-related difference in responses to ketamine is not fully understood. Abdalla et al. suggested the responses in infants may reflect an immaturity of innervation of the pulmonary vasculature and the myocardium. ${ }^{26}$ The enhanced responses with increasing age may reflect an increasing maturity of innervation in the pulmonary vasculature. ${ }^{16}$ We believe this explanation is unlikely since both infants and neonates have demonstrated increased pulmonary vascular reactivity to a variety of stimuli. ${ }^{27}$ Because ketamine has a dual effect on vascular smooth muscle (a direct effect causing vasodilatation and an indirect effect causing vasoconstriction), demonstrated in older animals, the net effect on the systemic vascular resistance is minimal. ${ }^{13,28}$ This result is demonstrated as well in the studies on children, ${ }^{16}$ infants ${ }^{17}$ and our own study in neonatal lambs.

Hickey et al. ${ }^{17}$ postulated that discrepancies in the effect of ketamine on the pulmonary vasculature were indirect effects of ketamine on the airway and ventilation. They demonstrated minimal haemodynamic response to ketamine in subjects whose airway and ventilation were maintained. This postulate is supported by studies in which haemodynamic changes were demonstrated only in association with significant changes in $\mathrm{pH}$ and $\mathrm{PO}_{2} \cdot{ }^{12,23,25}$

The increase in RR after ketamine in this study occurred although there was no evidence of hypoxia, hypercapnia or acidosis. The stability of the arterial blood gases leads us to speculate the increased RR was coincident with a decreased tidal volume, with the minute ventilation remaining unchanged. Adults breathing spontaneously in room air demonstrate significant reductions in arterial oxygenation and minute ventilation after the administration of ketamine $2 \mathrm{mg} \cdot \mathrm{kg}^{-1}$ intravenously as a rapid bolus. ${ }^{14.29}$ In contrast, patients premedicated with diazepam 10-15 mg intramuscularly and spontaneously breathing room air who received ketamine $2 \mathrm{mg} \cdot \mathrm{kg}^{-1}$ intravenously over 60 seconds showed no significant change in arterial oxygenation or shunt fraction. ${ }^{30}$ Furthermore, the administration of an infusion of ketamine $1 \mathrm{mg} \cdot \mathrm{kg}^{-1}$ intravenously during vaginal deliveries produced no significant changes in maternal or infant arterial blood gases. ${ }^{31}$ The respiratory response to carbon dioxide is maintained during ketamine anaesthesia and ketamine does not produce significant respiratory depression except when it is given as a rapid intravenous bolus. Increased RR has not been demonstrated previously and may represent an effect on an immature respiratory center or a reflex response to the injection of the drug into the left atrium, although such a reflex has not been described.

Care should be exercised when using ketamine in the critically ill newbom. Although we demonstrated no statistically significantly increase from control levels of HR or MAP, there is a trend towards an increase and the potential for increased cerebral perfusion pressure and consequently, cerebral blood flow is present. Because of the possible relationship between increased cerebral blood flow and intraventricular haemorrhage, blood pressure and heart rate must be monitored carefully during administration of ketamine.$^{32-34}$ Ketamine has no significant effect on the cardiovascular system in healthy neonatal lambs, but it does increase the respiratory rate although pulmonary gas exchange is unaffected. This confirms our clinical impression of the safety and stability of utilizing ketamine as a sedative/anaesthetic agent in healthy neonates.

\section{Acknowledgments}

The authors wish to thank Shue Lin Loo for her secretarial assistance and the Medical Publications Department, The Hospital for Sick Children, for their editorial assistance.

\section{References}

1 Bland JW, Williams WH. Anesthesia for treatment of congenital heart defects. In: AJ Kaplan, ed. Cardiac Anesthesia. New York: Grune and Stratton, 1979; 294.

2 Beynen FM, Tarhan S. Anesthesia for surgical repair of congenital heart defects in children. In: $\mathrm{S}$ Tarhan, ed. Cardiovascular Anesthesia and Postoperative Care. Chicago Year Book Medical Publishers, Inc. 1982; 73-180.

3 Hackel A. Anesthetic management of the pediatric patient. In: AK Ream, RP Fogdall, eds. Acute cardiovascular management: anesthesia and intensive care. Philadelphia: JB Lippincott Co, 1982; 614. 
4 Robinson S. Anesthesia for congenital heart disease. In: GA Gregory, ed. Pediatric Anesthesia. Vol. 2. New York: Churchill Livingstone, 1983; 607-43.

5 Dillon JB. Rational use of ketamine as an anaesthetic. Proc Roy Soc Med 1971; 64: 1153-6.

6 Szappanyos $G$, Gemperle M, Rifat $K$. Selective indications for ketamine anaesthesia. Proc Roy Soc Med 1971; 64: 1156-60.

7 Morgan M, Loh L, Singer L, Moore PH. Ketamine as the sole anaesthetic agent for minor surgical procedures. Anaesthesia 1971; 26: 158-65.

8 Cronin MM, Bousfield JD, Hewett EB, MCLellan I, Boulton $T B$. Ketamine anaesthesia for radiotherapy in small children. Anaesthesia 1972; 27: 13542.

9 Coppel DL, Dundee JW. Ketamine anaesthesia for cardiac catheterisation. Anaesthesia 1972; 27: 25-31.

10 White PF, Way WL, Trevor AJ. Ketamine - its pharmacology and therapeutic uses. Anesthesiology 1982; 56: 119-36

11 Takahashi K, Shima T, Koga $Y$ et al. Effect of ketamine hydrochloride (Ketalar) on the pulmonary hemodynamics. Jpn J Anaesth 1971; 20: 8426.

12 Gooding JM, Dimick AR, Tavakoli $M$, Corssen $G$. A physiologic analysis of cardiopulmonary responses to ketamine anesthesia in noncardiac patients. Anesth Analg 1977; 56: 813-6.

13 Liao JC, Kaehntop DT, Buckley JJ. Dual effect of ketamine on the peripheral vasculature (abstract). Anesthesiology 1979; 51: 5116.

14 Zsigmond EK, Matsuki A, Kothary SP, Jallad M Arterial hypoxemia caused by intravenous ketamine. Anesth Analg 1976; 55: 311-4.

15 Bini $M$, Reves $J G$, Berry D, Samuelson PN, Bargeron $L M J r$. Ejection fraction during ketamine anesthesia in congenital heart diseased patients (abstract). Anesth Analg 1984; 63: 186

16 Morray IP, Lynn AM, Stamm SJ, Herndon PS, Kawabori I, Stevenson JG. Hemodynamic effects of ketamine in children with congenital heart disease. Anesth Analg 1984; 63: 895-9.

17 Hickey PR, Hansen DD, Cramolini GM, Vincent $R N$, Lang $P$. Pulmonary and systemic hemodynamic responses to ketamine in infants with normal and elevated pulmonary vascular resistance. Anesthesiology 1985; 62: 287-93.
18 Chodoff $P$. Evidence for central adrenergic action of ketamine. Report of a case. Anesth Analg 1972; 51: 247-50.

19 Ivankovich AD, Miletich DJ, Reimann $C_{1}$ Albrecht $R F$, Zahed $B$. Cardiovascular effects of centrally administered ketamine in goats. Anesth Analg 1974; 53: 924-33.

20 Wong DHW, Jenkins $L C$. An experimental study of the mechanism of action of ketamine on the central nervous systm. Can Anaesth Soc J 1974; 21 : 57-67.

21 Tweed WA, Minuck M, Mymin D. Circulatory responses to ketamine anesthesia. Anesthesiology 1972; 37; 613-9.

22 Idvall $J$, Ahlgren I, Aronsen $K F$, Stenberg $P$. Ketamine infusions: Pharmacokinetics and clinical effects. Br J Anaesth 1979; 51: 1167-72.

23 Traber $D L$, Wilson $R D$, Priano $L L$. Differentiation of the cardiovascular effects of CI-581. Anesth Analg 1968; 47: 769-78.

24 Schwartz DA, Horwitz $L D$. Effects of ketamine on left ventricular performance. J Pharmacol Exp Ther 1975; 194: 410-4.

25 Tarnow J, Hess W, Schmidt D, Eberlein HJ. Narkoseeinleitung bei Patienten mit koronarer Herzkrankheit: Flunitrazepam, Diazepam, Ketamin, Fentanyl. Eine hämodynamische Untersuchung. Anaesthesist 1979; 28: 9-19.

26 Abdalla SS, Laravuso RB, Will JA. Effects of ketamine on pulmonary arteries (abstract). Anesthesiology 1982; 57: A79.

27 James $L S$, Rowe $R D$. The pattem of response of pulmonary and systemic arterial pressures in newborn and older infants to short periods of hypoxia. $J$ Pediatr 1957; 51: 5-11.

28 Diaz FA, Bianco JA, Bello A et al. Effects of ketamine on canine cardiovascular function. Br J Anaesth 1976; 48: 941-6.

29 Gassner S, Cohen $M$, Aygen M, Levy E, Ventura $E$, Shashdi $J$. The effect of ketamine on pulmonary artery pressure. An experimental and clinical study. Anaesthesia 1974; 29: 141-6.

30 Rust M, Landauer B, Kolb E. Stellenwert von Keta$\mathrm{min}$ in der Notfallsituation. Anaesthesist 1978; 27: 205-12.

31 Maduska AL, Hajghassemali M. Arterial blood gases in mothers and infants during ketamine anesthesia for vaginal delivery. Anesth Analg 1978; 57 : 121-3. 
32 Shapiro HM, Wyte $S R$, Harris AB. Ketamine anaesthesia in patients with intracranial pathology. $\mathrm{Br} \mathrm{J}$ Anaesth 1972; 44: 1200-4.

33 Takeshita $H$, Okuda $Y$, Sari A. The effects of ketamine on cerebral circulation and metabolism in man. Anesthesiology 1972; 36; 69-75.

34 Cabol LA, Siassi B, Artal R, Gonzalez F, Hodgman $J$. Cardiovascular and catecholamine changes after administration of pancuronium in distressed neonates. Pediatrics 1985; 75: 284-7.

\section{Résumé}

Afin de déterminer les effets respiratoires et cardiovasculaires de l'injection intra-veineuse de kétamine chez l'agnelet ont a étudié six préparations non prémédiquées. Chaque agnelet a été anesthésié avec la kétamine I $m g \cdot \mathrm{kg}^{-1}$ puis après le réveil ré-anesthésié avec $2 \mathrm{mg} \cdot \mathrm{kg}^{-1}$. La tension artérielle moyenne, la pression moyenne de l'artère pulmonaire, la pression moyenne de l'oreillette gauche, le flot pulmonaire sanguin, la fréquence cardiaque, la fréquence respiratoire, les gaz sanguins, ont été mesuré avant et après une, deux, quatre, six, huit et dis minutes de l'administration de chaque dose de kétamine. La résistance vasculaire pulmonaire, la résistance vasculaire systémique et leur rapport ont été déterminées. Après l'administration de la dose de kétamine, seule la fréquence respiratoire a changé significativement $(p<$ $0.05)$ atteignant un maximun après deux minutes. Ce changement n'était pas associé avec des anomalies des gaz sanguins. On conclut qu'en présence d'une ventilation adéquate, la kétamine ne produit pas d'effets cardiovasculaires significatifs chez les agnelets. 